\title{
Electronic Reference Tools in EFL Classes
}

\author{
Manssour Ras'n M. Habbash ${ }^{1}$ \\ ${ }^{1}$ Community College, University of Tabuk, Tabuk, Saudi Arabia \\ Correspondence: Manssour Ras'n M. Habbash, Community College, University of Tabuk, Tabuk, Saudi Arabia. \\ Tel: 966-54-696-6604. E-mail: research2015ut@gmail.com
}

$\begin{aligned} & \text { Received: October 18, } 2017 \quad \text { Accepted: November 1, } 2017 \quad \text { Online Published: December 23, } 2017 \\ & \text { doi:10.5539/ijel.v8n2p101 }\end{aligned}$ URL: http://doi.org/10.5539/ijel.v8n2p101

\begin{abstract}
Electronic reference tools viz. dictionaries, wikis, explorers, translators etc. tender a great support to the EFL learners in understanding different aspects of the lexical, syntactical, phonological and semantic complexities. In view of the usefulness of online reference tools, it is hypothesized that extensive use of the tools in classrooms expedites the acquisition of the language. In an effort to establish the correlation between the effective use of the tools and the acquisition of English as a foreign language, it is proposed to take up a study that aims at finding out the impact of using Electronic reference tools in EFL classrooms. The study was conducted with two groups of learners of English as a foreign language who completed their yearlong English language course that is mandatory for continuing their bachelors' course. By using purposive sampling method the participants of the study were selected and were divided into group A and group B based on the levels of success in their acquisition of English required for continuing their bachelor's courses. The levels of success were determined based on a diagnostic test conducted at the end of their one-year English language program, and graded in light of the Interagency Language Round Table Scale (ILRS). The students who obtained ILRS +3 level and above in the test were included in group A, and the students who obtained below ILRS 3 level are included in group B. The final sample of the students in both the groups were provided with a questionnaire of Likert scale that is followed by face-to-face interviews. By employing mixed method model of research, the correlation between their use of online reference tools and their level of success in learning the language were established. The results show a positive correlation that confirms the use of online and electronic reference tools is an essential learning strategy both within and out of the classroom learning as well as for expediting the learning process.
\end{abstract}

Keywords: Electronic reference tools, EFL teaching, ILR scale, learning strategies, student preferences

\section{Introduction}

English as a foreign language is taught in many Saudi Arabian universities with the goal of imparting their students with the English knowledge required for the continuation of their academics further at universities. The methods of instructions usually include classroom teaching under the tutelage of experienced teachers in well-appointed digital classrooms and the provision of online sources for individual and reflective practice. The EFL teachers are noticed to be using digital tools and online sources extensively in their classrooms to support their students acquire the language, and also suggesting their students to continue their practice of their language skills online. However, to what extent the use of online sources are supporting the acquisition of their skill in Speaking, Listening, Reading and Writing remains a question of inquiry in the case of Saudi Arabian EFL learners. In an effort to find the correlation between the use of online sources and the acquisition of language skills, a study is taken up at a university in Saudi Arabia. On the other hand the ministry of education in Saudi Arabia is focusing much on using online sources for teaching and practicing English and in this regard the ministry has undertaken to transform all the classroom that support the use of digital and online reference tools. On the whole, the online sources are available for the students via the latest touch screen mobiles, electronic notebooks and iPads, personal computers and laptops, language labs at the university and the libraries at the university. Apart from the openly available language practice sources, the students can also access books from the Saudi Arabian state digital library called Saudi Digital Library (SDL) that provides all kinds of electronic sources for practicing, researching and referencing. When looked at the advantages of using digital and online sources, we have volumes of deliberations and scholarly works that appear in the form of articles and books that find student motivation to practice and learn English, learner autonomy, learning accuracy and cost-efficiency as the major benefits of using the sources from the students' point of view. Moreover, it is understood that the 
students as well as teachers are well versed with the use of technology in terms of accessing data required online for the purpose of leaning, teaching and practicing English. In spite of the availability, usefulness, and the resourcefulness of the online sources, it is not certain to how far and to what extent the students are able to make use of the sources for furthering their English knowledge and performance. Driven by the hypothesis that the students' scores in the language tests reflect their knowledge of English, and that the students who scored well in their exams must have used the digital and online sources for enhancing their scores and knowledge of the language, this study aims at finding the correlations between the scores of the students and the extent of their use of online sources in enhancing their scores.

\section{Literature Review}

Integration of technology in teaching is either partially or completely done in most of the academic institutes all over the world. The integration of web in instruction has been a worldwide marvel of academics. The use of web is proved to be much useful for EFL instructors for classroom teaching, and for EFL learners for classroom learning as well as for out-of-the-class advanced learning. It is due to some cultural, regional and economical constraints that some of the institutes in some countries are lagging behind in this regard. Manca \& Ranieri (2013) find that the complete use of Facebook as an educational affordance tool is not determined. On the other hand, there are contradicting results from the studies conducted on its resourcefulness report contradicting results with some of them supporting its resourcefulness in terms of widening the context of learning, combining information and language learning and hybridization of expertise, while others point out the adversities in using Facebook in terms of cultural issues as well as the implicit pedagogies that the institutes, teachers and their students think more appropriate. Freeman \& Routen et al. (2013) write about the use of Communication and Information Technology (CIT) and about the Resource Based Learning (RBL) in Higher Education Institutes (HIE) that have taken the shape of virtual university. The integration of digital media by linking all the libraries and institutes creates a larger academic platform for online learning, which is much similar to the creation of National Grid for Learning in the UK. They also mention about the hybridization of institutes by which the integration of online sources for online learning takes place simultaneously with the real-time classroom based instruction and so learning happens in both ways.

Egbert \& Neville (2015) point out the necessity to improve media literacy especially amongst higher secondary school pupils. In the wake of the rampant Internet use of teenagers and adolescents for exploration and discovery of things, they suggest an intensive focus on improving the digital literacy in order to enable them to differentiate realities from fakes. Training EFL students on media literacy enhances their level of English as they are naturally more inclined and motivated to learn the language involved in media literacy as the literacy training requires the data that is similar to authentic instructional materials that are necessary for engaging EFL learners in language learning. Jarvis (2001) holds that the EAP and EFL are courses are for non-native English speakers who continue their further education in UK or any other English speaking countries. Jarvis maintains that the integration of ICT in the teaching of EFL and EAP requires the students to be provided with some training on accessing Internet sources and on evaluating the usefulness of information for learning purposes. The study carried out by Sinas \& Lin (2014) reveals considerable improvement in the language performance of the participants as reflected in the pre-test and post-test conducted for comparative analysis. It is understood that the participants are interested in reading the materials in English online as they are interesting mostly because they offer visualization of the content, personal motivation, the content that can be used for our choice situations like playing games, the content that they select for reading is of their existent level of their language efficiency and also because accessing and downloading the interesting content is easier.

Aljumah (2012) identified positive perceptions of students in using weblog and blogs in improving students writing composition. The use of blogs proves to be personally increasing the interest and motivation in using English for writing purposes. Teacher blogs and students' blogs create platforms for reading materials that ensue some discussion in the form of comments on the uploaded material and an immediate feedback on the comments. Since the materials that a student read are of their personal choice that would create additional interest in reading and responding. This kind of reading also triggers referencing with the help of online dictionaries, wikis and other such internet sources and involve the reader in the writing activity that automatically improves language performance in other way as well. Awada \& Ghaith (2014) bring forth their study of the use of WebQuest approach in improving writing composition and decreasing writing apprehension of Lebanese EFL learners. It is noted that the WebQuest activities involve a process that begins with a topic and an introduction to the topic that is followed by a preset stage of investigation using web sources online. The students will complete the writing project with the guidance from their teachers. The WebQuest method of teaching encourages students to use the online sources in improving their writing rather than just looking for information. The WebQuest project or 
activity ends with a concluding part by which the students will achieve the objective of the activity. Baniabdelrahman (2013) holds that online oral journals are a key part of EFL teaching and learning, as they take into consideration a more individual and nuanced utilization of the language in a protected situation. Making recordings and videos on the web using mobile phones offers the learners a chance to rehearse and check their language aptitudes anywhere with the minimal earlier preparation. The utilization of oral dairies with the primary year college students helped altogether to build their interest and their inspiration in English classes. The utilization of oral journals builds the learners' confidence in their capacities, by encouraging language practice once a day where ever the learner are, which is hard to accomplish once a day in any classroom. Furthermore, the utilization of oral journals provides the learners a chance to talk about their everyday activities and express their suppositions in English. Vo, Zhu, \& Diep's (2017) findings affirm that Blended Learning (BL) produces more learning outcomes, especially in STEM-disciplined courses, than the traditional classroom learning style. Blended learning is defined as a combination of classroom learning combined with computerized and e-learning. The mostly used online reference tools are dictionaries, glossaries, thesauruses, encyclopedias, search engines for general reference, dissertations and theses for research purposes, guides for writing, citing and style formation, history and politics references, the references for literature and mythology, medicine and healthcare and the references for science and math.

\section{Method}

Students of EFL at a university English language program are taken into consideration for the set study and the sample of students is taken by using purposive sampling method. Purposive sampling is the process of making a study sample by selecting the groups of units of informants purposefully with the presumption that the sample would give the researcher the same characters as the whole (Neyman, 1934). The students who completed their one-year English program were asked to take a diagnostic test for the purpose of estimating their level of success The test was conducted with the help of the EFL teachers who conducted the classes for the yearlong English language course for the students. The test was conducted for about 200 students and when the test was complete, it is found that only 156 students answered seriously to all the questions, and the rest of the answer sheets were discarded. Of the 156 students, 48 students scored above ILRS level +3 with 8 of them reaching the ILRS level 5, 14 of them reaching ILRS level 4 and with the other 26 remaining at level 3. All the students above ILRS 3 are taken into Group A ( $\mathrm{n}=48)$. Among the students who scored below ILRS 3, 38 of them scored ILRS level 2 and 52 of them obtained ILRS level 1 with the remaining 16 students at 0 level. The total number of students at level 2 and 1 are taken into Group B $(n=90)$. The 16 students at the 0 level are discarded from the study. A questionnaire that comprises a Likert scale was prepared and distributed to both the groups by hand for obtaining a quantitative data of the use of online reference tools for learning language, and conducted face to face interviews with a semi structured questionnaire for the sake of collecting the relevant data for qualitative analysis. In that way a mixed methods research model is employed for cross validation and for certainty of the results. Mixed methods or Triangulation is the use of a combination of quantitative and qualitative methods of research in the study of a same phenomenon and the simplest form of triangulation is the quantification of qualitative measure that is called scaling (Jick, 1979). The quantitative or dependent variable in this study is the level of language acquisition that is estimated in light of ILRS and the categorical or independent variable is the use of online reference tools. The quantitative analysis of the data is done using the analysis of variance (ANOVA) in order to establish the correlation between the dependent and the independent variables as well as the statistically significant differences between the means of the groups.

\section{Interpreting ILRS}

According to the Interagency Language Roundtable (n.d), the ILR scale was designed, for the first time, in 1955 by Foreign Service Institute (FSI) under the directives of the United States government. The scale underwent several modifications before it has taken its present shape. The scale in its present form is used to evaluate the language acquisition status of a language learner with its levels that range from $0-5$. The levels of language acquisition are marked with $0,0+, 1,1+, 2,2+, 3,3+, 4,4+$ and 5 for the skills of reading, writing, listening, speaking and other kind of language performances. For evaluating all the language skills, there are some basic descriptions by which one can understand the level of the knowledge of English and the ability to use the language in different contexts. So far, in the evaluation of any of the language skills by ILR Scale, the " 0 " refers to no practical ability to perform in the language and has no capability either to understand or comprehend the language to any extent. Level 1 learners can recognize the language elements at the very basic level that appear in language very commonly. Level 2 performers can understand the main idea with the direct meaning of the basic texts that contain familiar and factual expressions. However, at this level, the performers can't understand the connotations or implications in the text and they couldn't make any inferences from the text. The performers 
at level 3 can comprehend many things that are unfamiliar to them. However, they find it difficult to completely understand the texts that are out of their experiences and the ones that are linked to some external elements like cultural and societal norms. They can understand the texts pretty well when the texts are provided with some explanations. The performers at this level can hypothesize the things, can be argumentative and provide opinions. The performers at level 4 exhibit considerable fluency of the language use that is viewed as the professional use of the language. The performers at this level can make the meaning beyond the text with all the possible inferences as well as any cultural or social implications of the language. The language acquisition status of the level 5 performers is similar to that of the well-educated native speakers of the language. They can understand and respond to the most difficult prose, poetry etc., they can differentiate slangs, creoles and the different accent forms and can perform well in the contexts that are culturally variant.

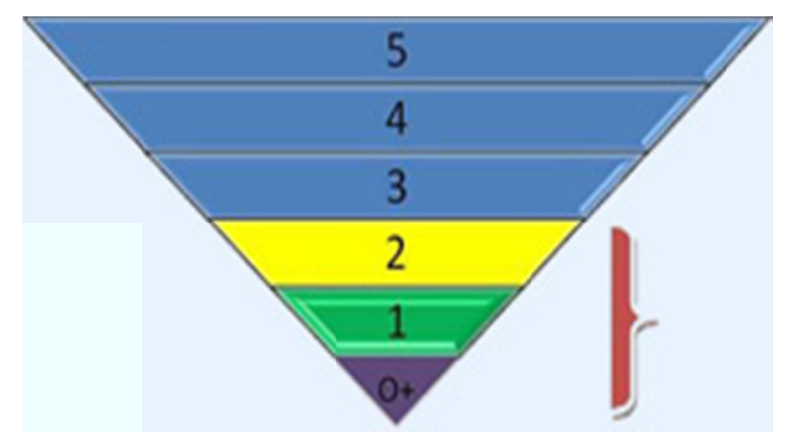

Figure 1. ILR scale

Source: http://www.govtilr.org/skills/ILRscale4.htm

\section{Data Analysis}

The triangulation of the data using mixed method of research is done by transferring the required quantitative information into tabular forms and is analyzed in light of the qualitative information that is taken in a narrative form. The data analysis reveals that the participants who used electronic sources have a major advantage in acquiring the language both in quality wise and quantity wise. The development of language in terms of clarity in the meanings of vocabulary or in the comprehension of reading texts becomes multiple times faster and accurate in the cases of the users of electronic reference tools. Although the numbers in table 1 and 2 reveal that almost all the students are in favor of using electronic reference tools, a closer look into the numbers in light of their scores in the diagnostic test reveals that the students who use the electronic reference tools extensively could acquire the language much better than those who don't use them. On the other hand, an analysis of the qualitative data taken from face to face interviews clarifies that the students with high motivational drive for learning the language tend to refer to the electronic reference tools much more frequently than their less motivated counter parts.

Table 1. Group A ( $\mathrm{n}=48$, ILRS $3+)$

\begin{tabular}{llllll}
\hline Q. No & Strongly Agree & Agree & Not Sure & Disagree & Strongly Disagree \\
\hline 1 & 32 & 16 & 0 & 0 & 0 \\
2 & 31 & 17 & 0 & 0 & 0 \\
3 & 42 & 4 & 0 & 1 & 1 \\
4 & 48 & 0 & 0 & 0 & 0 \\
5 & 38 & 6 & 0 & 2 & 2 \\
6 & 29 & 14 & 0 & 3 & 2 \\
7 & 45 & 3 & 0 & 0 & 0 \\
8 & 34 & 7 & 2 & 2 & 3 \\
9 & 28 & 12 & 0 & 5 & 3 \\
10 & 36 & 6 & 1 & 3 & 2 \\
11 & 39 & 3 & 0 & 4 & 2 \\
12 & 47 & 1 & 0 & 0 & 0 \\
13 & 48 & 0 & 0 & 0 & 0 \\
14 & 31 & 4 & 2 & 5 & 6 \\
15 & 35 & 5 & 5 & 2 & 1 \\
\hline
\end{tabular}


Table 2. $(\mathrm{n}=90$, ILRS $1 \& 2)$

\begin{tabular}{llllll}
\hline Q. No & Strongly Agree & Agree & Not Sure & Disagree & Strongly Disagree \\
\hline 1 & 52 & 14 & 6 & 16 & 2 \\
2 & 50 & 12 & 4 & 20 & 4 \\
3 & 58 & 6 & 6 & 10 & 10 \\
4 & 62 & 10 & 0 & 10 & 8 \\
5 & 64 & 4 & 4 & 12 & 6 \\
6 & 48 & 22 & 2 & 18 & 0 \\
7 & 54 & 20 & 4 & 10 & 2 \\
8 & 36 & 20 & 2 & 16 & 16 \\
9 & 50 & 16 & 0 & 14 & 10 \\
10 & 54 & 16 & 0 & 12 & 8 \\
11 & 64 & 0 & 6 & 16 & 4 \\
12 & 42 & 24 & 4 & 14 & 6 \\
13 & 40 & 24 & 4 & 14 & 8 \\
14 & 26 & 38 & 2 & 14 & 10 \\
15 & 28 & 28 & 8 & 18 & 8 \\
\hline
\end{tabular}

The total percentage of students who used electronic reference tools and online sources and are in favor of using the tools and sources are taken for analysis from the quantitative data. For the convenience of analysis, in spite of the degree of variance in their inclination towards using electronic reference tools, the cumulative percentages of the strongly agreed and the agreed are considered positively for using the online sources in learning English and the disagree and strongly disagree responses are considered cumulatively for the negative inclination towards using the sources for learning English. Also for the sake of convenience in putting data in tabular forms quantitatively the percentage of responses in favor of using or who used online reference tools are coded as AA for the responses that are positive to the reference tools in Group A and AD for the responses that are not positive in Group A. The percentage of responses that are against the use of electronic reference tools or who didn't use electronic tools are codes as BA for those that are positive to the reference tools in Group B and BD for those that are negative to electronic reference tools. The obvious variance between the participants who use electronic reference tools and those who are not in favor of using the tools reveals the benefits of the reference tools indisputably. The mode of the data in table no. 4 below refers to the undisputed advantages of using electronic reference tools. While the mode of the group A participants with regard to the agreement with the use of electronic reference tools is hundred percent that is only zero with regard to the disagreement of the use of the tools. With the mean of 91.7 showing the extent of the participants with regard to their using the reference tools the variance 71.6 points that the spread of the set data is not considerably wider, which further strengthens the study assumption.

Table 3. The basic data for analysis

\begin{tabular}{lllll}
\hline Q.No & $\mathrm{AA}((\mathrm{n}=48)$ Total and $\%$ & $\mathrm{BA}(\mathrm{n}=90)$ & $\mathrm{AD}(\mathrm{n}=48)$ & $\mathrm{BD}(\mathrm{n}=90)$ \\
\hline 1 & $48(100 \%)$ & $66(73.33 \%)$ & $0(0 \%)$ & $18(20 \%)$ \\
2 & $48(100 \%)$ & $62(68.88 \%)$ & $0(0 \%)$ & $24(26.6 \%)$ \\
3 & $46(95.83 \%)$ & $64(71.11 \%)$ & $2(4.1 \%)$ & $20(22.2 \%)$ \\
4 & $48(100 \%)$ & $72(80 \%)$ & $0(0 \%)$ & $18(26.6 \%)$ \\
5 & $44(91.66 \%)$ & $68(75.55 \%)$ & $4(8.3 \%)$ & $18(26.6 \%)$ \\
6 & $43(89.58 \%)$ & $70(77.77 \%)$ & $5(10.41 \%)$ & $18(26.6 \%)$ \\
7 & $48(100 \%)$ & $74(82.22 \%)$ & $0(0 \%)$ & $12(13.3 \%)$ \\
8 & $41(85.41 \%)$ & $56(62.22 \%)$ & $5(10.41 \%)$ & $32(35.5 \%)$ \\
9 & $40(83.3 \%)$ & $66(73.33 \%)$ & $8(16.66 \%)$ & $24(26.6 \%)$ \\
10 & $42(87.5)$ & $70(77.77 \%)$ & $5(10.41 \%)$ & $20(22.2 \%)$ \\
11 & $42(87.5)$ & $64(71.11 \%)$ & $6(12.5 \%)$ & $20(22.2 \%)$ \\
12 & $48(100 \%)$ & $66(73.33 \%)$ & $0(0 \%)$ & $20(22.2 \%)$ \\
13 & $48(100 \%)$ & $64(71.11 \%)$ & $0(0 \%)$ & $22(24.44 \%)$ \\
14 & $35(72.91 \%)$ & $64(71.11 \%)$ & $11(22.9 \%)$ & $24(26.6 \%)$ \\
15 & $40(83.3 \%)$ & $56(62.22 \%)$ & $3(6.25 \%)$ & $26(28.88 \%)$ \\
\hline
\end{tabular}


Table 4. Data for the effect seize

\begin{tabular}{lll}
\hline & AA & BA \\
\hline Mean & 91.7 & 72.7 \\
Standard Deviation & 8.46 & 5.66 \\
Mode & 100 & 71.1 \\
Variance & 71.6 & 32.03 \\
Std. Error of mean & 2.18 & 1.46 \\
\hline & AD & BD \\
\hline Mean & 6.79 & 24.7 \\
Standard Deviation & 7.14 & 4.87 \\
Mode & 0 & 26.6 \\
Variance & 51.09 & 23.7 \\
Std. Error of mean & 1.84 & 1.25 \\
Effect size: 3.11 & & \\
\hline
\end{tabular}

The effect size between the groups is calculated by using Hedges' g formula since the sample sizes in this study are much different.

The effect size "Hedges g" $=(24.7-6.79) / 5.75=3.11$

The effect size indicates a great different between the groups in terms of learning the language and it show that those who don't use electronic reference time are many times lagging behind when compared to their counter parts who use electronic reference tools extensively. When the two sets of the data related to the percentages of the participants that are in favor of using the reference tools are subjected to the analysis of variance (ANOVA) test, the outcome of the test shows greater significance between the means of the sets of data. As such the null hypothesis that can be assumed as learning that happens in the absence of the support of the reference tools can be equally faster and of high quality standards can be rejected with the $\mathrm{p}$ value less than .00001 .

Table 5. The data for ANOVA

\begin{tabular}{|c|c|c|c|c|c|}
\hline \multicolumn{6}{|c|}{ Summary of Data for ANOVA } \\
\hline & Treatments & & & & \\
\hline & 1 & 2 & 3 & 4 & Total \\
\hline $\mathrm{N}$ & 15 & 15 & & & 30 \\
\hline$\sum \mathrm{X}$ & 1376.99 & 1091.06 & & & 2468.05 \\
\hline Mean & 91.7993 & 72.7373 & & & 82.2683 \\
\hline$\sum \times 2$ & 127410.5371 & 79809.783 & & & 207220.3201 \\
\hline Std. Dev. & 8.4675 & 5.6631 & & & 12.0028 \\
\hline \multicolumn{6}{|l|}{ Result Details } \\
\hline Source & SS & & $\mathrm{df}$ & MS & $\mathrm{F}=52.52451$ \\
\hline Between-treatments & 2725.1988 & & 1 & 2725.1988 & \\
\hline Within-treatments & 1452.7612 & & 28 & 51.8843 & \\
\hline Total & 4177.96 & & 29 & & \\
\hline
\end{tabular}

Note. The $f$-ratio value is 52.52451. The $p$-value is $<.00001$. The result is significant at $p<.05$.

\section{Discussion and Conclusion}

Electronic reference tools have become easily accessible to most of the learning community in the world and the teachers of EFL and ESL have understood the importance of electronic reference tools in the context of teaching as well as leaning of a language. The most recent electronic reference apps that can be downloaded to mobiles and notebooks have made the references much more easier. The mobile applications like the 'speak and translate' have even replaced the necessity to learn a language, as a person in a place of a completely different language can manage the things get done with just such a mobile application downloaded into their mobile phones. Moreover, internet has become an indispensably essential need of human life just like food, water and clothing and some countries, in view of the importance of internet, have already declared it as an essential need of human life and many of the countries are thinking about providing it free for all their citizens. However, as it is expressed by many of the participating students in this study, there is still a great need to get the EFL and the ESL students much more closure to the e-reference tools, which is possible by an active participation of teachers in motivating the students and getting their students more used to the available e-reference tools. An analysis of the discussion helps in understanding that regular interactions about the new applications, the possibilities and 
the ways of using them in teaching and learning languages can support and expedite the process of acquisition of a language. Contrary to the traditional way of learning a language through the literature available in the language, electronic reference tools can support in learning a language by bringing the native language data base in its pure form as well as its variants to the learners all over the world, which can make it possible to have a direct exposure to the language by creating a virtual environment of the language context.

In spite of multiple advantages of using electronic reference tools, one major drawback that some educators argue against the use of the tools remains the point of distraction. Especially among the student community in Saudi Arabia, the major argument against the electronic reference tools is that the students tend to use them for different other purposes than for educational purposes. However, the results in this study show that the extensive users of electronic reference tools are benefited a lot better than the non-users in terms of having opportunities to listen to different accent forms including the native ones, speak to different people, writing to various contexts as well as comprehending complex texts. The reasons for lagging behind in improving language via electronic reference tools are multifaceted that stem from many other aspects of a student life other than the distractions with the electronic gadgets. The major reasons are likely to be the ones like student motivation, learning attitude, personal vision of their careers where they can use their language skills etc. It is suggestible that the teachers of EFL need to keep working on their understanding about, and the use of the newly developing electronic reference tools in their teaching and keep improving the motivational levels of their students toward using the tools for educational purposes.

\section{References}

Al-Asmari, A. M. (2005). The use of the Internet among EFL teachers at the colleges of technology in Saudi Arabia (Doctoral dissertation, The Ohio State University).

Aljumah, F. H. (2012). Saudi learner perceptions and attitudes towards the use of blogs in teaching English writing course for EFL majors at Qassim University. English Language Teaching, 5(1), 100-116. Retrieved from http://files.eric.ed.gov/fulltext/EJ1079098.pdf

Altawil, A. (2016). Exploring How Digital Media Technology Can Foster Saudi EFL Students' English Language Learning. International Association for Development of the Information Society. Retrieved from http://files.eric.ed.gov/fulltext/ED571592.pdf

Awada, G., \& Ghaith, G. (2014). Impact of using the WebQuest technological model on English as a foreign language (EFL) writing achievement and apprehension. Arab World English Journal, 81-93.

Baniabdelrahman, A. A. (2013). Effect of using internet tools on enhancing EFL students' speaking skill. Journal of Contemporary Research, 3(6), 79-87.

Dziemianko, A. (2010). Paper or electronic? The role of dictionary form in language reception, production and the retention of meaning and collocations. International Journal of Lexicography, 23(3), 257-273. https://doi.org/10.1093/ijl/ecp040

Egbert, J., \& Neville, C. (2015). Engaging K-12 Language Learners in Media Literacy. TESOL Journal, 6(1), 177-187. https://doi.org/10.1002/tesj.182

Freeman, H., Patel, D., Routen, T., Ryan, S., \& Scott, B. (2013). The virtual university: The internet and resource-based learning. London, New York: Routledge.

Interagency Language Roundtable. (n.d.). An overview of the history of the ILR Language proficiency skill level descriptions and scale by Dr. Martha Herzog. Retrieved from http://www.govtilr.org/skills/Audio_trans.htm\#preface

Jarvis, H. (2001). Internet usage of English for academic purposes courses. ReCALL, 13(02), 206-212. https://doi.org/10.1017/S0958344001000623a

Jick, T. D. (1979). Mixing qualitative and quantitative methods: Triangulation in action. Administrative Science Quarterly, 24(4), 602-611. https://doi.org/10.2307/2392366

Manca, S., \& Ranieri, M. (2013). Is it a tool suitable for learning? A critical review of the literature on Facebook as a technology-enhanced learning environment. Journal of Computer Assisted Learning, 29(6), 487-504. https://doi.org/10.1111/jcal.12007

Neyman, J. (1934). On the two different aspects of the representative method: the method of stratified sampling and the method of purposive selection. Journal of the Royal Statistical Society, 97(4), 558-625. https://doi.org/10.2307/2342192 
Sinas, S., \& Lin, S. S. P. (2014). Usage of English Materials from the Internet to Improve Students' Language Performance. Procedia-Social and Behavioral Sciences, 134, 193-200. https://doi.org/10.1016/j.sbspro.2014.04.239.

Sulaimani, A. (2016). Teaching and learning in Saudi Arabia: perspectives from higher education. Asian Englishes, 18(1), 85-87. http://dx.doi.org/10.1080/13488678.2016.1142706

Vo, H. M., Zhu, C., \& Diep, N. A. (2017). The effect of blended learning on student performance at course-level in higher education: A meta-analysis. Studies in Educational Evaluation, 53, 17-28. https://doi.org/10.1016/j.stueduc.2017.01.002

\section{Appendix A}

\section{The Questionnaire with Likert Scale}

1. I use online reference tools for improving my English.

2. I depend on online reference tools more than my class teacher for clarifications.

3. I use online dictionaries every time that I doubt the meaning of a word.

4. I use Internet search engines like the Google almost everyday to have clarifications on my English language doubts.

5. Online reference tools are great motivational sources of learning.

6. Learning a language becomes much easier when I keep verifying my classroom knowledge by online reference tools.

7. Understanding culture-based communication is much easier and authentic via online reference tools.

8. When using online sources for shopping and for any information I intentionally choose English language because I know that my English improves drastically by doing so.

9. I consider reviewing chat room discussions and comments in response to the answers provided by different people to the questions posed with regard to grammar and the use of language.

10. I refer to multiple online sources like dictionaries, thesauruses and visual thesauruses for clarity and complete understanding of any single concept that I am interested in learning.

11. While writing, I refer to online sources for clarity of my expression and for content as well.

12. English pronunciation practice is much better through online sources. I used online sources for improving my English pronunciation.

13. Online reference tools help in translating the passive knowledge of English into the active knowledge of my English repertoire.

14. Understanding lengthier and complex concepts of English can be done at a relaxed pace with the desirable completeness of the information required.

15. Etymological explanations that are handy to refer by online sources can help in strengthening my vocabulary.

\section{Appendix B}

\section{Diagnostic Test}

1. Choose the correct words.

I went goed shopping yesterday.

1) Are you watching / Do you watch TV at the moment?

2) They not saw / didn't see the match.

3) We sleeped / slept really badly.

4) Do you want to / Want you to go to the cinema?

5) What was / were they talking about?

6) You hardly ever phone / phone hardly ever me.

7) Was he watching / Did he watching a comedy? 
8) How often are you speaking / do you speak to him?

9) Do you must / Do you have to drive on the right in your country?

10) You must / should take an umbrella—it's going to rain.

2. Look at the online catalogue for sports equipment. Then circle the correct answers.

\begin{tabular}{|ll|}
\hline \multirow{2}{*}{\begin{tabular}{l} 
good \\
\multicolumn{1}{c|}{ very good }
\end{tabular}} \\
\hline Ball (small) & $€ 20 \quad * * * * * * *$ \\
Ball (big) & $€ 30 \quad * * * *$ \\
Water bottle (small) & $€ 8 \quad * * * * *$ \\
Water bottle (big) & $€ 10 \quad * * * * *$ \\
Table tennis table & $€ 200 \quad * * * * *$ \\
Tennis racket & $€ 35 \quad * * * * *$
\end{tabular}

1) The small water bottle is cheaper than / more

2) expensive than / the most expensive the big water bottle.

3) The big ball is not as expensive as / not as cheap as / as expensive as the tennis racket.

4) The table tennis table is cheaper than / more expensive than / the most expensive item in the catalogue.

5) The cheap ball is bigger than / smaller than / as big as the other ball.

6) The balls are as good as / better than / not as good as the table tennis tables.

7) The small water bottle is cheaper than / as cheap as / the cheapest item in the catalogue

3. Write sentences from the prompts using the present simple, present continuous, past simple or past continuous tense.

1) you / watch TV / at the moment / ?

2) They / not see / the match / yesterday

3) We / sleep / badly / last night

4) What / they / talk about / when I called / ?

5) How often / you / see / your grandparents / ?

4. Complete the sentences with the words below. Use too ... or (not) ... enough. busy $\bullet$ big $\bullet$ old $\bullet$ far $\bullet$ loud $\bullet$ warm / too loud

1). I can't hear you. The radio is

2). You can't put all your clothes in that bag. It's

3). I can't come to your house today. I'm

4). We can't go swimming today. It's

5). Bill is eighteen. He is to drive a car.

\section{Circle the correct answers.}

Eleven-year-old Keith is one of the ${ }^{1}$ better / best / good enough young surfers in Britain. Keith lives in Scotland. The Scottish sea is ${ }^{2}$ coldest / cold enough / colder than the sea in the rest of Britain. But it isn't ${ }^{3}$ too 
cold / colder / coldest for Keith. He loves the sea and he thinks surfing is ${ }^{4}$ more exciting than / the most exciting / too exciting sport in the world. Now, Keith is ${ }^{5}$ old enough / as old as / older to enter competitions. He wants to be a champion

\section{Complete the conditional sentences using the verb in brackets.}

If it rains tomorrow, we'll stay (stay) at home.

1) If I pass the exam, I (have) a party.

2) If they were hungry, they (eat) the food.

3) They wouldn't call me if there (not be) a problem.

4) What would you do if time (stop)?

5) If we had seen your brother, we (give) him the money.

6) (go) to bed very early.

7) If we sell the car, you You won't be able to sleep if you

8) If I had known your email, I (have) to walk to school.

\section{Rewrite the sentences using the going to or will form of the verb in brackets.}

1) $\mathrm{I}$ (go) shopping tomorrow, so I (be) poorer when I get home.

2) I (attend) the school meeting tonight, so I all the school's plans.

3) They (build) on the park, so we (lose) our green space.

4) $\mathrm{We}$ (not see) you tonight because we (get) home late.

\section{Complete the sentences using the present or past passive.}

\section{Present passive}

1) __ the plates (make) from recycled paper?
2) The date (announce) today.
3) Shampoo (not sell) at the bank.
4) The news (read) by a man.

\section{Past passive}

5) The article (write) yesterday.

6) The parents (not invite).

7) My house (build) last year.

8) The man (identify) by a child.

\section{Complete the questions and answers.}

1) What $?$

I'm watching TV.

2) Did they see the match yesterday?

Yes,

3) How ?

I slept really badly last night.

4) What ?

We were talking about football when you called.

5) How ?

I see my grandparents about once a week. 
6) Did you go to the museum?

Yes,

10. Look at the table and write rules and advice.

\begin{tabular}{|l|l|l|l|l|}
\hline & PROHIBITION & OBLIGATION & ADVICE & NOT NECESSARY \\
\hline take an umbrella & & & $\checkmark$ & \\
\hline wear a uniform & & & & $\checkmark$ \\
\hline park there & $\checkmark$ & & & \\
\hline pay $£ 5$ & & $\checkmark$ & & \\
\hline tell her & & & $\checkmark$ & \\
\hline
\end{tabular}

1)

2)

3)

4)

\section{Complete the conditional sentences using the verbs in brackets.}

If it rains (rain) tomorrow, we'll stay (stay) at home.

1) If I (get) a good mark tomorrow, I (invite) you to dinner.

2) If I (see) him later, I (give) him the book.

3) They (not tease) me if I (not be) so shy.

4) What you (do) if you (win) the lottery?

5) If we we (find) your umbrella, (call) you.

6) You (not be) able to work if you (listen) to music at the same time.

7) If we (sell) the car, you (have) to walk to school.

8) If I (know) your sister, I (meet) her at the station.

\section{Make passive sentences.}

1) The art teacher copied the masterpiece.

2) They didn't sell the house at auction.

3) The exhibition didn't impress the visitors.

4) Does plastic poison the atmosphere?

\section{Complete the sentences with the words.}

are announced are given is made

isn't sold was built was published were sent weren't informed 
1) The table from wood.

2) The church last century.

3) Toothpaste at the baker's.

4) The children home from school.

5) The book yesterday.

6) The parents until Tuesday.

7) The winners today.

8) The prizes by the President.

14. Complete the present perfect sentences with the words.

already for hasn't haven't just since still 've yet

I know! He's already told me.

1) I haven't seen him he was five.

2) Have you downloaded the software ?

3) $\mathrm{He}$ hasn't given me a birthday present.

4) She visited the Prado because she's never been to Madrid.

5) They've been together a long time.

6) They invited us three times to their party, but we're always busy.

7) $\mathrm{He}$ 's left.

8) We still read that book.

\section{Reading}

\section{STUDENTS AND TECHNOLOGY}

When my dad was at school, there weren't any computers and the internet didn't exist. He didn't communicate with his friends by email and he didn't make new friends in chat rooms online.

These days the answer to almost every question is on your computer. How has this influenced the way we study? Firstly, we can find information much more easily than we could in the past. You don't need to search through books and encyclopaedias. You can enter your key words in a search engine and then choose from the many websites which can give you the information you need.

Secondly, there are also websites which give advice and practical help with essays and other homework. Sometimes you have to pay for this, but there are a lot which are free. Some people think this is cheating, but if you write the essay yourself, you won't just copy text. You will also learn.

\section{All in all, I think we're lucky today. Studying is a lot more fun!}

\section{Read the text. Then read the sentences and write true or false.}

The writer's dad had a computer at school. False

1) The writer's dad used email a lot.

2) Today it's harder to find information.

3) Some homework websites are free.

4) The writer thinks homework websites can help you learn.

5) The writer thinks studying was more fun when her dad was at school.

\section{Read the text. Then answer the questions using your own words.}

1) Where is the answer to almost every question?

2) What do you enter in a search engine? 
3 Where can you find advice and practical help?

4) Are all the homework websites free?

5) How does the writer describe studying today?

\section{Read the text. Then find words in the text for the definitions.}

1). An area on the Internet or other computer network where users can communicate, typically one dedicated to a particular topic.

2). Try to find something by looking or otherwise seeking carefully and thoroughly

3) Books containing factual information

4) Act dishonestly or unfairly in order to gain an advantage

5) Fortunate

4. Tick $(\checkmark)$ the true sentences and correct the false sentences.

1) The writer's dad didn't make new friends.

2) _ We can get a lot of information through our computers.

3) The writer thinks homework websites are cheating.

4) Students today are luckier than before.

5) You will also learn using the information from the Internet.

\section{Writing}

Choose one option (100 words)

1) Write an opinion essay with this title: Are you in favour of using mobile phone into the classroom?

2) Write an email to a friend telling him or her what you would like to study in the future and why.

3) Write the advantages and disadvantages of social networks.

Option:

Title of the essay: 


\section{Copyrights}

Copyright for this article is retained by the author(s), with first publication rights granted to the journal.

This is an open-access article distributed under the terms and conditions of the Creative Commons Attribution license (http://creativecommons.org/licenses/by/4.0/). 